\title{
THE
}

5-28-2014

\section{Introduced and Native Congeners Use Different Resource Allocation Strategies to Maintain Performance During Infection}

\author{
Courtney A.C. Coon \\ Amber J. Brace \\ Scott R. McWilliams \\ University of Rhode Island, srmcwilliams@uri.edu \\ Marshall D. McCue \\ Lynn B. Martin
}

Follow this and additional works at: https://digitalcommons.uri.edu/nrs_facpubs

Terms of Use

All rights reserved under copyright.

\section{Citation/Publisher Attribution}

Coon, C., Brace, A., McWilliams, S., McCue, M., \& Martin, L. (2014). Introduced and Native Congeners Use Different Resource Allocation Strategies to Maintain Performance during Infection. Physiological and Biochemical Zoology: Ecological and Evolutionary Approaches, 87(4), 559-567. doi:10.1086/676310 Available at: http://dx.doi.org/10.1086/676310

This Article is brought to you for free and open access by the Natural Resources Science at DigitalCommons@URI. It has been accepted for inclusion in Natural Resources Science Faculty Publications by an authorized administrator of DigitalCommons@URI. For more information, please contact digitalcommons-group@uri.edu. 


\section{CHICAGO JOURNALS}

Division of Comparative Physiology and Biochemistry, Society for Integrative and Comparative Biology

Introduced and Native Congeners Use Different Resource Allocation Strategies to Maintain Performance during Infection

Author(s): Courtney A. C. Coon, Amber J. Brace, Scott R. McWilliams, Marshall D. McCue, and Lynn B. Martin

Source: Physiological and Biochemical Zoology, Vol. 87, No. 4 (July/August 2014), pp. 559-567

Published by: The University of Chicago Press. Sponsored by the Division of Comparative

Physiology and Biochemistry, Society for Integrative and Comparative Biology

Stable URL: http://www.jstor.org/stable/10.1086/676310

Accessed: 18/06/2015 09:25

Your use of the JSTOR archive indicates your acceptance of the Terms \& Conditions of Use, available at

http://www.jstor.org/page/info/about/policies/terms.jsp

JSTOR is a not-for-profit service that helps scholars, researchers, and students discover, use, and build upon a wide range of content in a trusted digital archive. We use information technology and tools to increase productivity and facilitate new forms of scholarship. For more information about JSTOR, please contact support@jstor.org. 


\section{Introduced and Native Congeners Use Different Resource Allocation Strategies to Maintain Performance during Infection}

\author{
Courtney A. C. Coon ${ }^{1, \star, \dagger}$ \\ Amber J. Brace ${ }^{1, *}$ \\ Scott R. McWilliams ${ }^{2}$ \\ Marshall D. McCue ${ }^{3}$ \\ Lynn B. Martin ${ }^{1}$ \\ ${ }^{1}$ Department of Integrative Biology, University of South \\ Florida, Tampa, Florida 33620; ${ }^{2}$ Department of Natural \\ Resources Science, University of Rhode Island, Kingston, \\ Rhode Island 02881; ${ }^{3}$ Department of Biological Sciences, St. \\ Mary's University, San Antonio, Texas 78228
}

Accepted 2/21/2014; Electronically Published 5/28/2014

Online enhancements: appendix, tables.

\begin{abstract}
Hosts can manage parasitic infections using an array of tactics, which are likely to vary contingent on coevolutionary history between the host and the parasite. Here we asked whether coping ability of congeners that differ in host-parasite coevolutionary history differed in response to experimental infections with a coccidian parasite. House sparrows (Passer domesticus) and gray-headed sparrows (Passer griseus) are sympatric and ecologically similar, but house sparrows are recent colonizers of Kenya, the site of our comparison, whereas gray-headed sparrows are native. We evaluated three variables as barometers of infection coping ability: vertical flight, pectoral muscle size, and fat score. We also measured routing of a dose of ${ }^{13} \mathrm{C}$-labeled leucine, an essential amino acid, among tissues to compare resource allocation strategies in response to infection. We found that burden effects on performance were minimal in both species, but house sparrows maintained considerably higher burdens than gray-headed sparrows regardless of exposure. House sparrows also had more exogeneous leucine tracer in all tissues after $24 \mathrm{~h}$, demonstrating a difference in the way the two species allocate or distribute resources. We argue that house sparrows may be maintaining larger resource reserves to mitigate costs associated with exposure and infection. Additionally, in response to increased parasite exposure, gray-headed sparrows had less leucine tracer in their spleens and more in their gonads, whereas house sparrows did not change allocation, perhaps
\end{abstract}

* These authors contributed equally to this article.

$\dagger$ Corresponding author; e-mail: ccoon@mail.usf.edu.

Physiological and Biochemical Zoology 87(4):559-567. 2014. (C) 2014 by The University of Chicago. All rights reserved. 1522-2152/2014/8704-3111\$15.00. DOI: $10.1086 / 676310$ indicating a trade-off that is not experienced by the introduced species.

\section{Introduction}

Expression of many life history characteristics, such as reproductive parity and investment in particular immune components, is intimately linked with availability of resources (Stearns 1992). Trade-offs occur when resources are limited because investment in one process ultimately results in fewer resources for other processes (Stearns 1992; Roff 1993). Due to expenses associated with maintenance, induction, and mitigation of the immune system, costs of immunity are likely significant mediators of host evolution, especially when a host experiences a major alteration in parasite diversity and infection risk, such as frequently occurs during host introductions and range expansions (Torchin et al. 2003; Colautti et al. 2006). How an introduced host responds to these changes in parasite pressures in its new range could, in part, influence its introduction success (Lee and Klasing 2004; Martin et al. 2010b). In particular, previous studies have supported the idea that trade-offs and subsequent changes in resource allocation facilitate invasion success and range expansions (Blossey and Notzold 1995; Lee and Klasing 2004; Phillips et al. 2010), but none has yet tested this hypothesis directly.

The goal of our study was to investigate how infection with a ubiquitous, generalist intestinal protozoan parasite affected individual health and altered allocation of an essential nutrient in a successful introduced species, house sparrows (HOSP; Passer domesticus), compared to a native congener, gray-headed sparrows (GHSP; Passer griseus). HOSP are native to the Middle East and Europe but have established populations across the globe, including our study site in Nakuru, Kenya, in the 1990s (Lewis and Pomeroy 1989; Martin et al. 2014). In general, HOSP have lost many of their specialist parasites during introductions (Manwell 1957; Brown and Wilson 1975; Marzal et al. 2011) but appear to be highly competent reservoirs for many generalist parasites in their introduced territories (Komar et al. 2003; Lee et al. 2005; Reisen et al. 2005).

HOSP and GHSP are similar in terms of diet, body size, and behavior, and the two often cohabitate, suggesting that parasite exposure risk is comparable, at least for environmentally transmitted parasites. Yet, as GHSP are native and HOSP are introduced, coevolutionary history with local parasites should differ between the two species. As such, we first compared resistance and tolerance in HOSP and GHSP. Resistance refers to a host's 
ability to avoid or clear infections, whereas tolerance is defined as the slope of a regression between host fitness and parasite burden (Raberg et al. 2009). Ecologically, tolerance represents a host's ability to maintain fitness during infection (Sears et al. 2011). Given their longer evolutionary history with local parasite strains, we expected native GHSP to better resist infection, resulting in lower burdens during a natural infection and after experimental exposure under controlled conditions. Conversely, though infections may be more likely in native HOSP, we hypothesized that HOSP would tolerate coccidia infections better because tolerance may provide an indirect mechanism that HOSP could utilize to outcompete natives (Kelly et al. 2009; Martin et al. 2010b; Dunn et al. 2012). Here, we used three performance metrics to estimate tolerance: abdominal fat score, pectoral muscle size, and vertical flight.

In an effort to reveal the underlying mechanism by which species cope with infection, we also compared nutrient allocation strategies in response to parasite exposure between species. In both experimentally exposed and unexposed (but still infected) birds, we measured allocation of a dose of ${ }^{13} \mathrm{C} 1$ labeled L-leucine (hereafter ${ }^{13} \mathrm{C}$ leucine), an essential amino acid that cannot be synthesized by the body yet is a critical component of virtually every protein therein. Because ${ }^{13} \mathrm{C}$ leucine is typically rare in the body, an exogenous dose can be given and serve as a proxy for determining rates of protein synthesis in individual tissues. In this way ${ }^{13} \mathrm{C}$ leucine can then be tracked to monitor nutrient allocation (McCue 2011). We hypothesized that experimental exposure would cause GHSP to allocate relatively more ${ }^{13} \mathrm{C}$ leucine to tissues associated with immune responses (liver and spleen) to facilitate parasite clearance (i.e., resistance). We predicted that HOSP would respond by investing relatively more ${ }^{13} \mathrm{C}$ leucine in gonads and pectoral muscle to maintain reproductive and physical performance during infection in order to maintain competitive ability (Kolar and Lodge 2001; Whitney and Gabler 2008).

\section{Material and Methods}

\section{Capture and Husbandry}

HOSP and GHSP were captured in mist nets in Nakuru, Kenya $\left(0^{\circ} 17^{\prime} \mathrm{S}, 36^{\circ} 4^{\prime} \mathrm{E}\right)$, in March and April of 2012 . Sex was determined at capture for HOSP (externally dimorphic) and at necropsy for GHSP (externally monomorphic). Prior to experimental exposure, birds were kept in two flocks (split by species) in outdoor enclosures, approximately $1.5 \mathrm{~m} \times 1 \mathrm{~m} \times 1.5 \mathrm{~m}$, within a few meters of each other. Birds were fed a mix of dried rice, millet, and sorghum ad lib. Hard-boiled chicken eggs, cooked fine cornmeal, and fresh fruit were offered several times weekly. Prior to the experiment, birds were medicated with sulfadimethoxine, an anticoccidial and antibiotic drug, used as directed by the manufacturer for poultry, dissolved at a concentration of $\sim 0.05 \%$ in the drinking water and provided continuously except where noted below. Infections are not cleared by sulfadimethoxine (Brawner et al. 2000); rather, the drug inhibits the first, asexual stage of coccidia replication in the host (Reid 1990). As such, sulfadimethoxine blocks the costs associated with acute infection and any further increases in burden as a result of parasite exposure during captivity. The drug does not, however, block the second, sexual stage reproduction, so (chronic) parasite burden was relatively constant and indicative of capture burden despite nonexperimental parasite exposure that may have occurred during captivity.

During the 11-d experiment, birds were housed in small single-species groups (one to four birds) in conventional songbird cages $(35.6 \mathrm{~cm} \times 40.6 \mathrm{~cm} \times 44.5 \mathrm{~cm})$. The experiment was run in two consecutive iterations beginning in April and ending in May. For the first $4 \mathrm{~d}$ of the experiment (prior to experimental exposure), all birds were given unmedicated water so residual medication would not interfere with experimental infections for experimentally exposed birds and for consistency in the control groups. Parasite exposure (or control [vehicle] exposure) was performed on experiment day 5. Postexposure, control birds again received water with sulfadimethoxine to maintain burdens. Experimentally exposed birds were given unmedicated water. All procedures met guidelines for the use of animals in research and were approved by the University of Southern Florida Institutional Animal Care and Use Committee (W3202) and the Kenyan Ministry of Science and Technology.

\section{Parasites}

Coccidia were used for experimental infections because (i) they are generalist, fecal-orally transmitted parasites; (ii) accurate quantification of shedding and standardization of exposure is possible; (iii) oocyst (egg) peak shedding is typically consistent from day to day (Greiner 1989a); (iv) rates of oocyst shedding closely correlate with intestinal burden (Dolnik 2006); and (v) coccidiosis can be lethal for some passerines (Hõrak et al. 2004; Greiner 1989a). The particular species of coccida used in this study, Isospora lacazei (family Eimeriidae; E. Greiner, personal communication), has a relatively broad geographical and host range within passerines (Levine 1982), though local adaption of haplotypes is likely common (Schrenzel et al. 2005; Dolnik et al. 2009). In infected chickens, oocysts are released in the feces 4-5 d postinfection, with peak shedding 6-9 d postinfection, followed by chronic shedding (Allen and Fetterer 2002). Immune responses occur most strongly during the first $6 \mathrm{~d}$ postinfection (Allen and Fetterer 2002). Thus, the first $6 \mathrm{~d}$ postinfection (experiment days 5-11) tend to be more costly per unit time as compared to the chronic phase of infection (Dolnik and Hoi 2010). Oocyst shedding follows a diel periodicity in passerines, with the major peak in shedding occurring 2-4 h before sunset (Boughton 1933; Kruszewicz 1995; Lopez et al. 2007). Once shed, oocysts undergo a period of sporulation to become infectious. We designed our study to overlap the times during which effects of exposure should be most observable. 


\section{Oocyst Quantification}

Oocyst shedding rate was determined for each bird on the first day of the experiment (day 1 ), the day of experimental exposure (day 5), and the last day of the experiment (day 11). The oocyst quantification protocol was adapted for the field from Dolnik (2006). Briefly, birds were individually placed in cloth bags $\sim 3$ $\mathrm{h}$ before sunset until a single fresh fecal pellet could be collected (within $1 \mathrm{~h}$ ). Pellets were preserved at room temperature in a $2 \%$ potassium dichromate solution until sugar flotations could be carried out $(<1 \mathrm{wk})$. Quantification of oocysts was performed by washing the oocysts three times with water before adding $40 \%$ saturated sucrose solution to float the oocysts (Greiner 1989b; Dolnik 2006). A 20- $\mu \mathrm{L}$ sample was taken from the middle of the flotation solution surface, placed on a glass slide, and examined immediately. This method provides a relative oocyst count per fecal pellet, not oocyst per gram feces. In other species, this method is preferred because it accounts for bird size, is correlated with gut parasite burden, and is not affected by desiccation as weighing methods under field conditions can be (Dolnik 2006).

\section{Experimental Exposure}

Oocysts for experimental infections were obtained using the following adapted protocol (Hõrak et al. 2004, 2006). To begin, dozens of fecal pellets were collected from the bottoms of cages of eight HOSP and eight GHSP, $14 \mathrm{~d}$ before experimental exposure of the first cohort. Samples from both species were pooled and then divided into several replicates. Each replicate was mixed with water and then strained, after which oocysts were allowed to settle to the bottom of the tube before supernatant was removed and a $2 \%$ potassium dichromate solution added. The mixture was sporulated at room temperature for 7 $\mathrm{d}$, with daily aeration. After $1 \mathrm{wk}$, oocysts from each replicate were examined daily to ensure sporulation. Once more than $90 \%$ of examined oocysts were infectious, oocysts were kept in sealed containers at room temperature until experimental exposures were performed.

On the day of coccidia exposure (day 5), the potassium dichromate supernatant was removed, the remaining residue was washed four times, and the oocysts were floated as described. A 2-mL sample was taken from the surface of the float (where the viable oocysts were located) and placed in a clean tube with enough water to dilute the sugar solution. Once the oocysts precipitated to the bottom of the tube, the supernatant was removed until only $1 \mathrm{~mL}$ of residue remained. The residue was homogenized and the average of five subsamples used to determine the starting oocyst concentration. Cages of birds of each species were randomly selected to be in one of three groups: control birds were given $100 \mu \mathrm{L}$ of water, low-dose birds were given 200 oocysts in $100 \mu \mathrm{L}$ water, and high-dose birds were given 2,000 oocysts in $100 \mu \mathrm{L}$ water. All treatments were given orally.

\section{Performance Metrics}

Physical performance was measured for each bird on day 2 and day 10, offset from fecal pellet collection to minimize handling stress. During each test, abdominal fat deposits were scored from 1 to 8 (ordinal scale, 8 maximum; Kaiser 1993) and pectoral muscle width (to $1 \mathrm{~mm}$ ) was measured with calipers for each individual by the same person. Pectoral width is a proxy for pectoral muscle mass (Davidson 1979) and potential muscle power (Hill 1950), as well as protein reserves (Davidson 1979), and has been used previously as a performance metric for HOSP (Martin et al. 2011, 2012). Birds were also challenged to perform vertical flight (Martin et al. 2012), an important method of predator avoidance. Because the maneuver involves both jumping and vertical flight, it is often considered one of the most energetically expensive movements birds can make (Veasey et al. 1998). For this challenge, a 0.5-m section of nylon cord with $1.3-\mathrm{g}$ weights every $10 \mathrm{~cm}$ was attached to an individual's left leg (Altshuler et al. 2010). Birds were then video recorded as they were placed at the bottom of a $15 \times 15 \times$ $150-\mathrm{cm}$ wood-framed box covered in clear plastic sheeting and then harassed by hand, always by the same researcher, for 30 s. The summed height $(\mathrm{cm})$ of all flights during a 30-s trial was used during analyses.

\section{Leucine Allocation}

On day 10, 10 control birds ( $n=5$ HOSP and 5 GHSP) and 35 experimentally exposed birds (HOSP: $n=10$ high dose, $n=8$ low dose; GHSP: $n=9$ high dose, $n=8$ low dose) were orally gavaged with a single $20-\mathrm{mg}$ dose of ${ }^{13} \mathrm{C}$ leucine, $99 \%$ suspended in $200 \mu \mathrm{L}$ of sunflower oil (Cambridge Isotopes, Cambridge, MA), as previously described (McCue et al. 2010). As the leucine was incorporated into tissues, so too was the ${ }^{13} \mathrm{C}$ tracer. Twenty-four hours after administration, birds were euthanized by rapid decapitation under deep isoflurane anesthesia. Immediately after euthanasia, biopsies from the liver and pectoral muscle and entire spleens and gonads were removed and frozen in liquid nitrogen until transfer to the United States, upon which samples were kept at $-40^{\circ} \mathrm{C}$ until lyophilized and prepared for isotope analysis (McCue et al. 2010). Isotope ratio mass spectrometry analysis was performed at the US Environmental Protection Agency, Atlantic Ecology Division Laboratory, in Narragansett, Rhode Island, with a Vario microelemental analyzer interfaced with an Isoprime 100 isotope ratio mass spectrometer (Elementars America, Mt. Laurel, NJ).

The ${ }^{13} \mathrm{C}$ values in the tissues were recorded in terms of $\delta^{13} \mathrm{C}_{\mathrm{VPDB}}$ (Slater et al. 2001; Werner and Brand 2001). Background $\delta^{13} \mathrm{C}$ values measured in the tissues of birds that were not exposed to the ${ }^{13} \mathrm{C}$ tracer were used to calculate the $\delta^{13} \mathrm{C}$ enrichments resulting from the exogenous ${ }^{13} \mathrm{C}$ leucine tracer. These enrichments (in $\delta$ units) were log transformed to achieve normality and then divided by body mass to adjust for minor differences in organ mass (McCue 2011), which can affect tracer distribution. We expressed these $\delta^{13} \mathrm{C}$ enrichments in terms of 
$\log \delta$ per gram, and these values were used as a proxy for leucine allocation (hereafter absolute leucine allocation). We also compared the relative leucine allocation to the lymphoid tissues in terms of allocation to the gonad tissue (i.e., absolute allocation to splenic or hepatic tissues divided by absolute allocation to gonadal tissue; sensu McCue et al. 2013), as well as the weighted leucine allocation (i.e., the absolute leucine in a particular tissue divided by the total absolute leucine in all tissues measured); the resulting ratios were unitless.

\section{Analyses}

A repeated-measures ANOVA revealed that exposure dose (low vs. high) did not affect burden differently (GHSP: Scheffé post hoc test, low vs. high, $P=0.474$; HOSP: Scheffé post hoc test, low vs. high, $P=0.904$ ) and no performance metric differed between low- and high-dose-exposure groups (data not shown). For this reason, we combined the two doses into a single experimentally exposed group for each species for all analyses. For many analyses we refer to preexposure and postexposure variables, by which we mean experiment day 1 and day 11 , respectively. In other analyses we used the change in performance or burden, which was calculated by subtracting day 11 values from day 1 values. We performed all analyses using both raw and body-size-adjusted performance variables (performance divided by mass $[\mathrm{g}]$ ), but as outcomes were similar, we report analyses of only raw data here. All statistics were performed in IBM SPSS Statistics, version 21.0.

Resistance and Tolerance. Traditionally, resistance is defined as the inverse of burden after exposure of an uninfected individual (Raberg et al. 2009). However, even prior to the experiment, every bird was infected with coccidia. Subsequently, we used repeated-measures ANOVA to compare burden based on species and exposure (experimentally exposed vs. the control group) and their interaction, which would reveal differences in relative resistance in response to experimental exposure. We also compared initial burden with an independent $t$-test to determine whether preexposure burden was different between species. Last, we were interested in whether initial burden could predict change in burden in experimentally exposed birds; thus, we used ANCOVA with change in burden as the dependent variable and species and preexposure burden as the independent variables. Prior to analyses, coccidia burdens were $\log _{10}+1$ transformed to achieve normality. All other continuous dependent variables were normally distributed based on histograms, skewness values, and kurtosis statistics.

We investigated possible tolerance differences using general linear models (GLMs), asking whether species differed in how average postexposure burden affected average postexposure performance (dependent variable: postexposure performance; independent variables: postexposure coccidia burdens, species, and their interaction; data: experimentally exposed birds only). A significant burden $\times$ species interaction term would suggest species differences in tolerance.
Resource Allocation. Analyses of resource allocation were performed using linear mixed models except where otherwise noted. We first performed an analysis with individual as a random effect to ask how species, tissue, and their interaction affected absolute leucine allocation. We then analyzed whether exposure and burden affected absolute leucine allocation. We were also interested in whether differences in weighted leucine allocation existed between the two species, so we compared the effects of tissue, species, exposure, and their two- and threeway interactions, as well as postexposure coccidia burden on ${ }^{13} \mathrm{C}$ leucine incorporation. Last, to determine whether species allocated leucine differently among liver and gonad or spleen and gonad (termed relative leucine), we assessed the effects of exposure, species, their interactions, and coccidia burden on the ratios of one tissue to another (liver : gonad, spleen : gonad) using GLMs.

\section{Results}

Initial analyses suggested that there was a cohort effect on performance but not burden for HOSP and GHSP. As such, we included cohort as a covariate for analyses of performance (i.e., tolerance) but not for other analyses (appendix, available online).

\section{Parasite Burden and the Effects of Burden on Performance}

HOSP shed over 10 times as many oocysts as GHSP prior to experimental coccidia exposure $\left(F_{1}=15.01, P<0.005\right.$; fig. $1 A)$. Burden in control groups remained low over the experimental period in both species, indicating that the anticoccidial drug was effective in maintaining burden (fig. $1 B$ ). In experimentally exposed groups, both HOSP and GHSP increased burdens after experimental exposure, though HOSP had significantly higher burdens both before and after experimental exposure (fig. $1 \mathrm{~B}$, table $\mathrm{A} 1$; tables $\mathrm{A} 1$ and $\mathrm{A} 2$ available online). Yet, there was no exposure $\times$ species interaction, indicating no differences in resistance. For both HOSP and GHSP, preexposure coccidia burdens were significantly negatively correlated with change in coccidia burdens postexposure $\left(F_{1}=35.58\right.$, $P<0.0005)$, with HOSP sustaining significantly larger burdens than GHSP $\left(F_{1}=13.86, P=0.001\right.$; fig. 2$)$. As indicated in figure 2 , there appears to be a maximum rate of shedding in both species, but the maximum is higher for HOSP than GHSP. Last, burden did not affect any of the three performance metrics for experimentally exposed HOSP or GHSP (fig. 3; table A2); thus, tolerance did not differ between species.

\section{Resource Allocation}

HOSP had more absolute leucine in all tissues than GHSP after $24 \mathrm{~h}$ (species: $\left.F_{1,39.3}=37.8, P<0.0005\right)$ and tissues had significantly different amounts of leucine (tissue: $F_{3,98.4}=99.3$, $P<0.0005$ ). Absolute leucine allocation patterns (to all tissues measured) also differed between species (tissue $\times$ species interaction: $F_{3,98.4}=4.24, P=0.007$; fig. $4 A$ ). Weighted leucine 

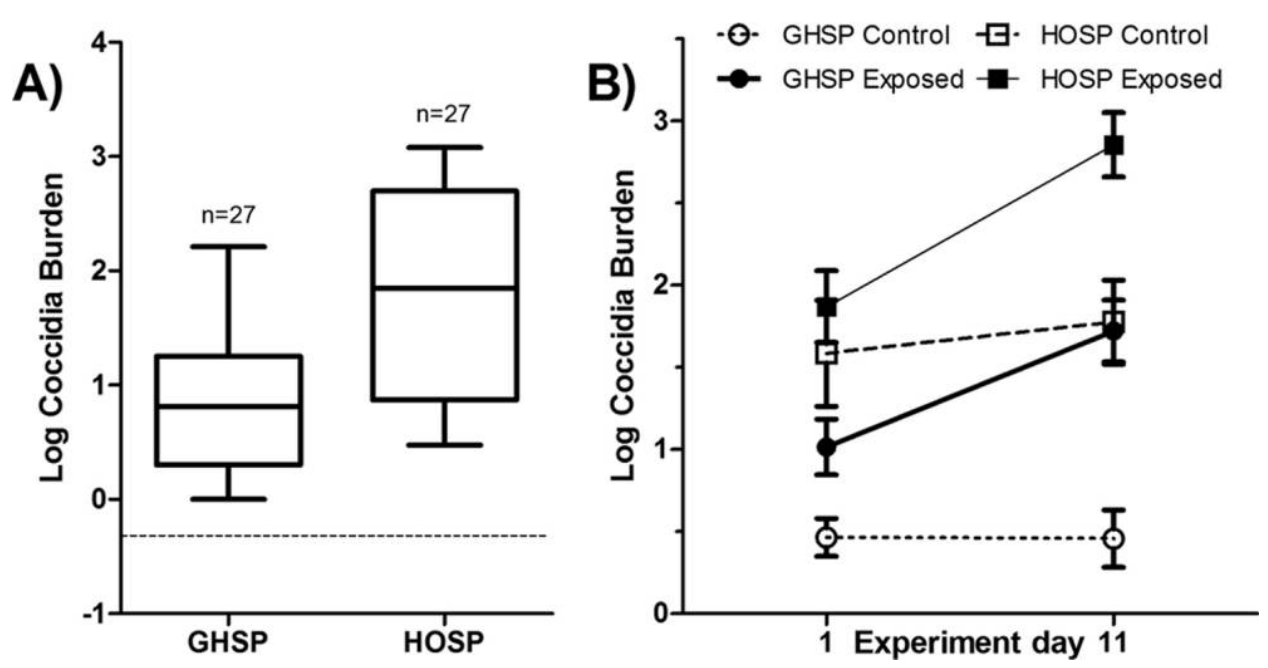

Figure 1. House sparrows (HOSP) shed significantly more coccidia than gray-headed sparrows (GHSP) pre- and postexperimental exposure. $A$, The boxplot illustrates that on experiment day 1, prior to exposure, all birds of both species were infected with coccidia, though HOSP had significantly higher burdens than GHSP $(P<0.0005)$. Error bars show minimum to maximum values, box indicates upper and lower quartiles, and midline denotes mean. $B$, Both species experienced similarly significant increases in burden after experimental exposure to coccidia compared to controls (time: $P=0.033$; species: $P<0.0005$; exposure: $P<0.0005$; species $\times$ time $\times$ exposure: not significant). Error bars are \pm 1 SE.

allocation differed among tissues $\left(F_{3,63}=77.51, P<0.0005\right)$, with a significant species $\times$ tissue interaction $\left(F_{3,63}=4.09\right.$, $P=0.010)$. Separate GLMs revealed that GHSP had greater weighted allocation of leucine to spleens than HOSP (GHSP: mean $=0.4134, \mathrm{SD}=0.062$; HOSP: mean $=0.3238, \mathrm{SD}=$ 0.052; $P=0.004$; fig. $4 B)$. However, burden $\left(F_{1,63}=0.033\right.$, $P=0.856)$ and species $\left(F_{1,63}=1.773, P=0.188\right)$ were not significant predictors. When examining leucine allocation to the liver relative to the gonad, neither species $\left(F_{1}=1.46, P=\right.$ $0.238)$ nor exposure $\left(F_{1}=0.42, P=0.522\right)$ was a significant predictor. However, a significant species $\times$ exposure interaction was found $\left(F_{1}=4.66, P=0.041\right)$, with lower relative allocation to the liver in exposed GHSP than unexposed GHSP but no difference in HOSP due to exposure (fig. $5 A$ ). Species $\left(F_{1}=8.19, P=0.009\right)$ and exposure $\left(F_{1}=5.63, P=0.026\right)$ were significant predictors of differences in leucine allocation to the spleen relative to the gonads (fig. $5 B$ ); however, no significant species $\times$ exposure interaction was present $\left(F_{1}=2.21\right.$, $P=0.151)$.

\section{Discussion}

We hypothesized that differences in coevolutionary history among HOSP, GHSP, and a local Kenyan coccidian parasite would lead to variation in how hosts coped with and allocated an essential resource in response to infection. Our first prediction, that GHSP would be more resistant than HOSP, was not supported. All birds in the study were naturally infected prior to capture, and both species had similar increases in burden after experimental exposure. In both species, initial burden significantly predicted change in burden postexposure. Importantly, though, HOSP shed more than 10 times as many oocysts as GHSP before and after experimental exposure, which may have implications for the success of the former as an invader. Our second prediction, that HOSP would be more tolerant than GHSP, was also not supported. Both species tolerated coccidia well, even when burden was increased experimentally. Our third prediction, that HOSP would allocate more of an essential amino acid toward tissues that maximized reproductive and physical performance rather than immunity, was also not supported. However, species did allocate leucine differently. Specifically, HOSP had more leucine tracer in all tissues at the time of sampling than GHSP. Additionally, exposed GHSP had

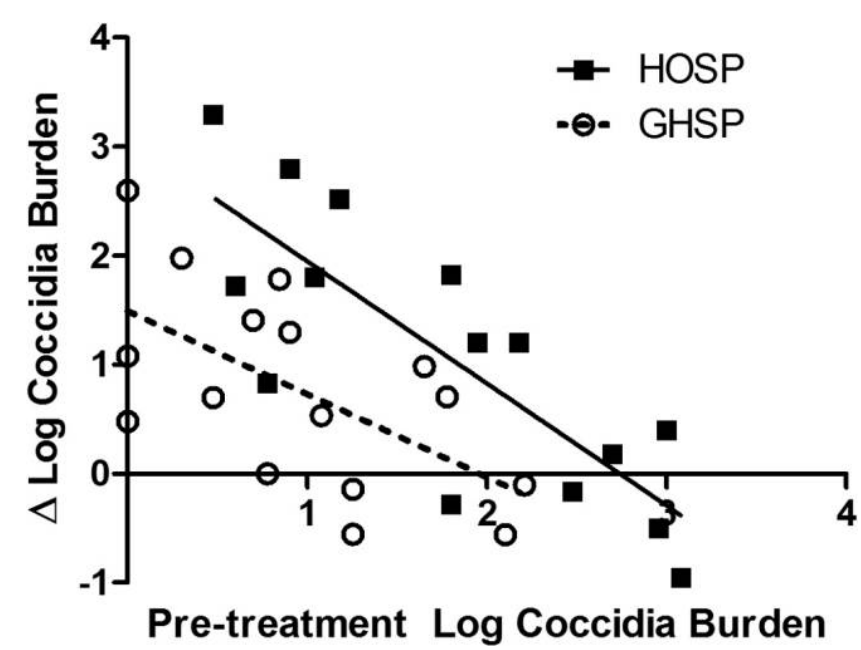

Figure 2. Coccidia burden on experiment day 1 significantly negatively predicted change $(\Delta)$ in coccidia burden over the 11-d experiment $(P<0.0005)$. Burden was significantly higher for house sparrows (HOSP) than for gray-headed sparrows (GHSP; $P=0.001$ ). 

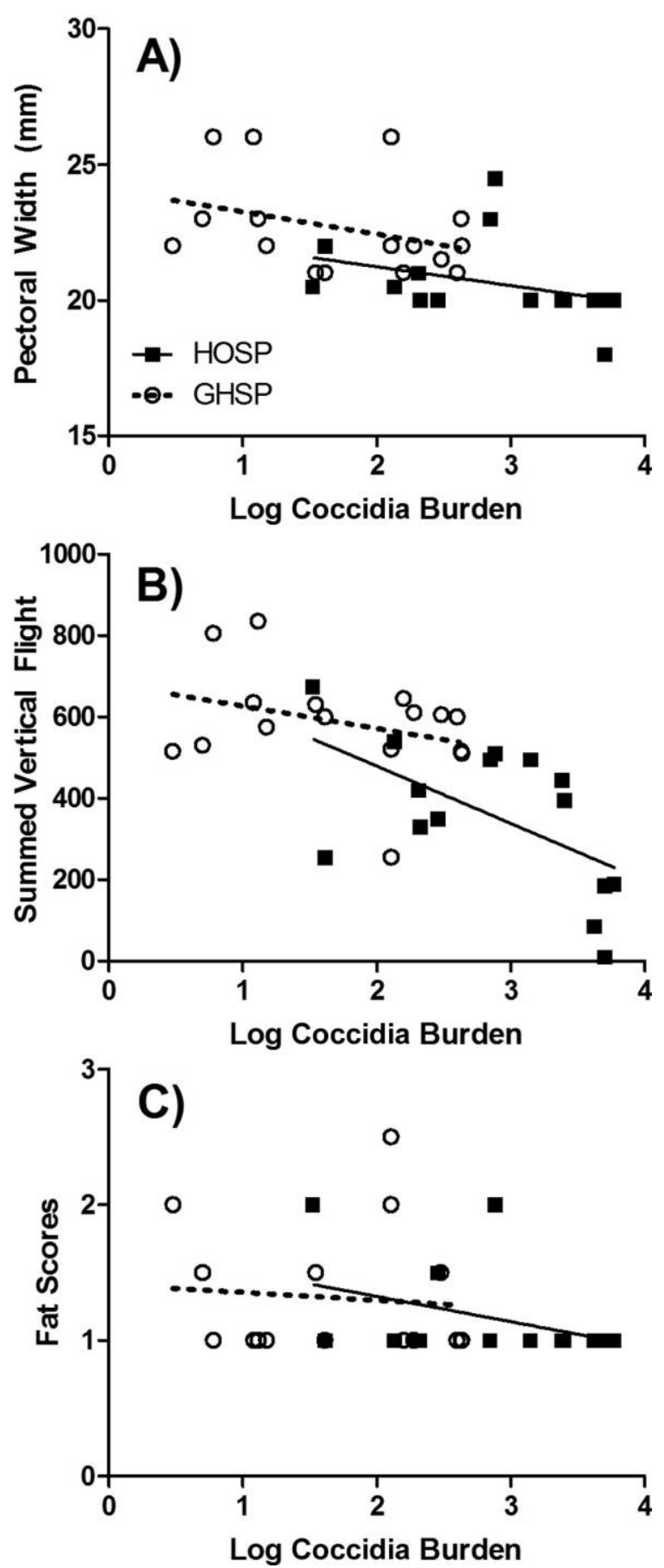

Figure 3. Tolerance of coccidia infections did not differ between house sparrows (HOSP; squares, solid line) and gray-headed sparrows (GHSP; circles, dashed line) for pectoral width $(A)$, vertical flight $(B)$, or fat scores $(C)$. Data are from experiment day 11 (6 d postinfection) for exposed individuals only.

more leucine tracer in gonads relative to liver, whereas HOSP had similar amounts of ${ }^{13} \mathrm{C}$ leucine regardless of exposure. These outcomes suggest a trade-off in response to acute coccidia infection in the native species but not the introduced species, though it could also be an artifact due to the constraints of our experimental design. Below, we interpret these outcomes with respect to their impacts on the Kenyan HOSP range expansion as well as coccidia dynamics in avian communities.

\section{Burden and Performance}

Our experimental data indicate that these two host species have similar levels of resistance (fig. 1) and tolerance (fig. 3) to coccidia infections. These results may partially be explained by this ecotype of Isospora lacazei being relatively avirulent or because Passer coping responses to coccidia are effective and conserved. Yet the fact that host performance was similar despite very different parasite burdens is intriguing. How and why do HOSP incur and endure such high burdens? One possibility is that HOSP have higher burdens because they engage in behaviors that put them at increased risk of exposure, such as by disproportionately eating food contaminated by infected feces (Dolnik et al. 2010). Alternatively, gut morphology could differ between HOSP and GHSP, giving the parasites more space in which to encyst. This possibility seems unlikely given that the two species have similar diets and are about the same body

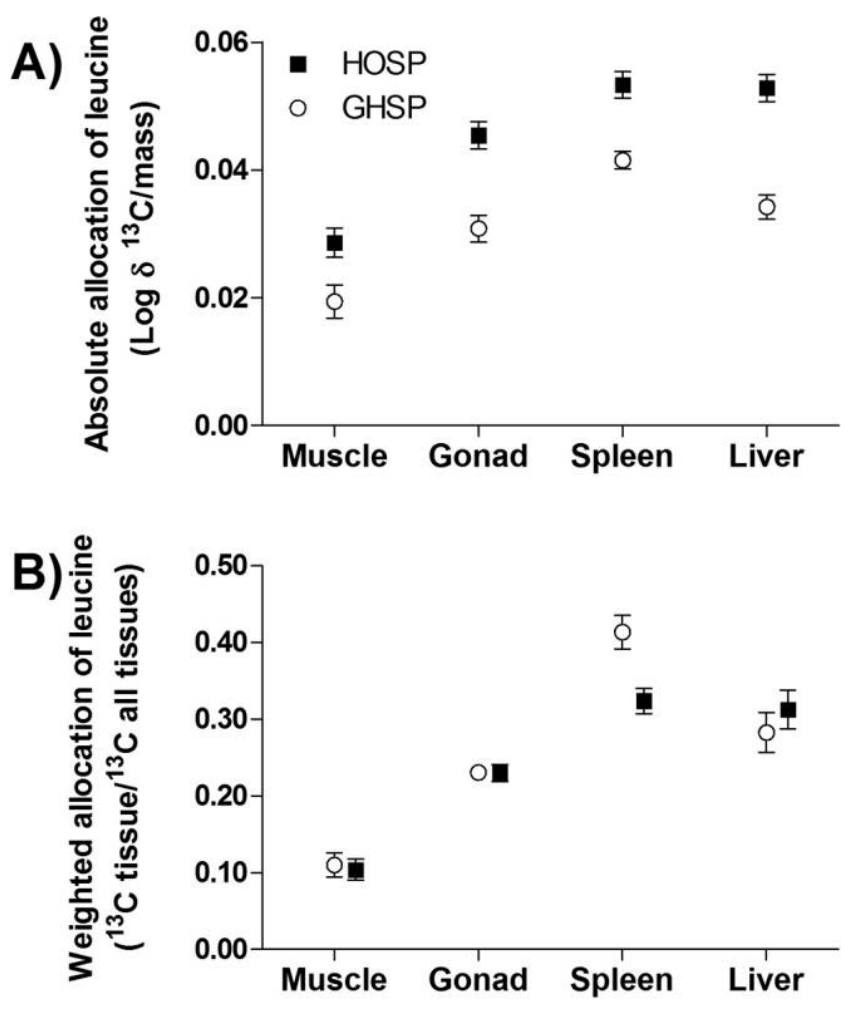

Figure 4. Exogenous ${ }^{13} \mathrm{C}$ leucine measured among four tissues in native gray-headed sparrows (GHSP) and introduced house sparrows (HOSP). A, HOSP had more ${ }^{13} \mathrm{C}$ leucine in all tissues, and HOSP and GHSP allocated ${ }^{13} \mathrm{C}$ leucine differently among tissues (species: $P<$ 0.0005; tissue: $P<0.0005$; species $\times$ tissue: $P<0.007) . B$, HOSP allocated ${ }^{13} \mathrm{C}$ leucine more consistently (weighted allocation: proportion of total measured leucine among measured tissues) among tissues than GHSP (species: $P=0.188$; tissue: $P<0.0005$; species $\times$ tissue: $P=0.010)$. Error bars are \pm 1 SE. 

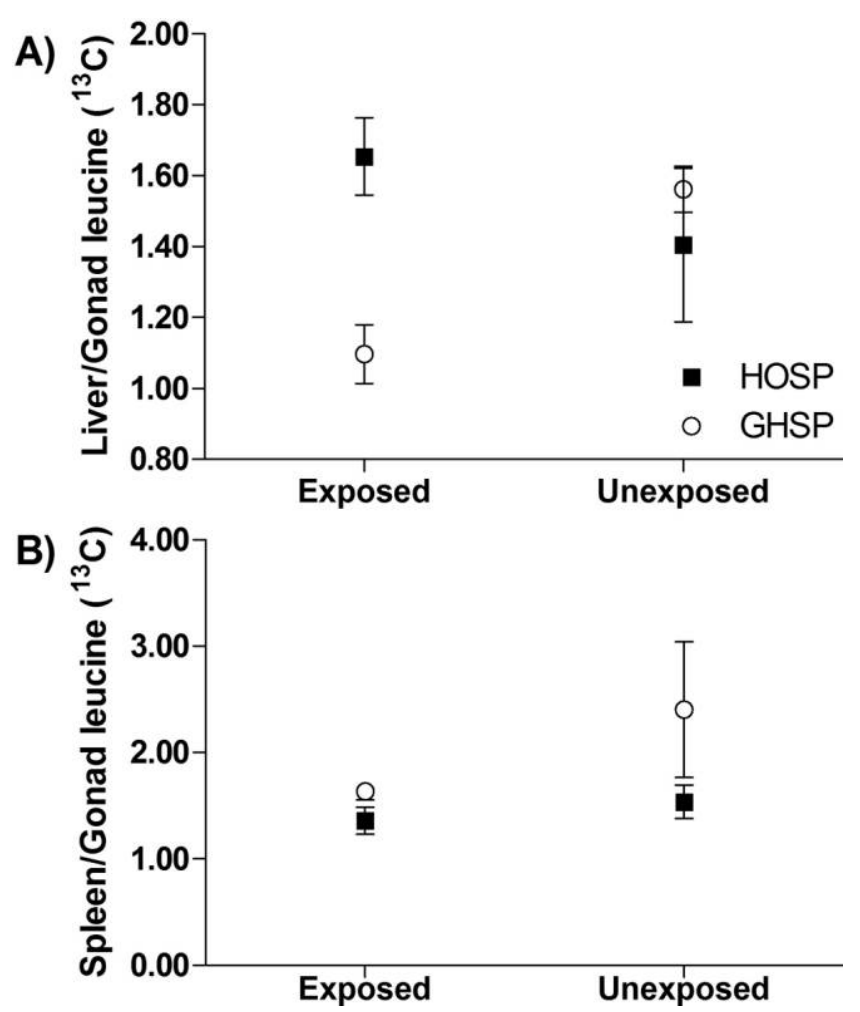

Figure 5. Ratios of ${ }^{13} \mathrm{C}$ leucine in immune tissue (liver and spleen) relative to reproductive tissue differed significantly between house sparrows (HOSP) and gray-headed sparrows (GHSP). A, Coccidia-exposed GHSP had less ${ }^{13} \mathrm{C}$ leucine in liver relative to gonad tissue, whereas exposure did not impact ${ }^{13} \mathrm{C}$ leucine ratios in HOSP (species: $P=$ 0.238 ; exposure: $P=0.522$; species $\times$ exposure: $P=0.041) . B$, Species $(P=0.009)$ and exposure $(P=0.026)$ affected ${ }^{13} \mathrm{C}$ leucine allocation in spleen relative to gonad tissue, but exposure effects were indistinguishable between species (species $\times$ exposure: $P=0.151$ ). Error bars are \pm 1 SE.

size (Ricklefs 1996; Lavin et al. 2008). A third possibility is that HOSP delay resistance responses until burden surpasses a higher threshold than GHSP, as is suggested by our finding that initial burden is predicted by change in burden postexposure (fig. 2). Although this possibility should be tested directly, such a strategy may be valuable or even necessary for introduced species given that one major cost of infection in hosts lacking an evolutionary history with a parasite is collateral damage from inflammatory reactions (Lee and Klasing 2004; Martin et al. 2010b; Sears et al. 2011).

Ecologically, the high burdens that HOSP maintain may increase the frequency of parasite exposure for other avian hosts in the community (Restif and Koella 2004; Horns and Hood 2012), an outcome termed parasite spillback (Kelly et al. 2009). As HOSP shed many coccidia but experience minimal health impacts themselves, spillback may enable HOSP to outcompete some native hosts (Kelly et al. 2009). There is already anecdotal evidence that HOSP employ parasite spillback in their introduced range in North America, where they are increasing ex- posure of native cliff swallows (Petrochelidon pyrrhonota) to a native arbovirus (O’Brien et al. 2011).

\section{Optimal Defense Strategies}

We found evidence that HOSP and GHSP may use different resource allocation strategies when coping with coccidia infections. First, HOSP had more leucine tracer in all tissues after $24 \mathrm{~h}$ compared to GHSP. Though this measure was taken at a single time point and thus must be interpreted cautiously, it suggests that HOSP (i) more rapidly or more efficiently assimilate leucine, (ii) oxidize more leucine during digestion for immediate use in tissues, and/or (iii) metabolize or export leucine more slowly from tissues than GHSP. Though factors such as differences in burden or response to coccidia may influence absolute leucine assimilation, any of these mechanisms could provide HOSP with a larger nutrient pool from which to draw and buffer costs of acute infection. One promising test of this possibility would be to constrain further availability of nutrients, which may reveal trade-offs among systems that were masked in this study (Ruiz et al. 2011).

A second distinction in allocation between HOSP and GHSP was the relative distribution of leucine among tissues. Overall, GHSP had relatively more leucine tracer in their spleens than HOSP both before and after experimental coccidia exposure. One interpretation of this pattern is that native species have a relatively greater investment in (splenic) immunity. Similar patterns of low immune investment have been observed before in introduced HOSP, although not at the level of resource allocation to tissues (Lee et al. 2005, 2006; Martin et al. 2010a). We expected GHSP would allocate more leucine to spleens and livers in response to coccidia exposure as compared to HOSP. However, we found that experimentally exposed GHSP allocated more leucine tracer in their gonads than livers (lower liver : gonad ratios) as compared to unexposed GHSP (fig. 5A), while HOSP allocation patterns did not vary with coccidia exposure. This species difference might reflect a resource tradeoff in GHSP that is avoidable by HOSP, perhaps because of a greater absolute assimilation of leucine in HOSP (fig. $4 A$ ). If GHSP are employing immune mechanisms to keep their burdens low, it is possible that experimentally exposed GHSP are exporting immune proteins from spleen and liver faster than control GHSP. Consequently, it may appear as though exposed GHSP are allocating less leucine to lymphoid tissue when in fact they are exporting leucine more rapidly to minimize burden. Such an interpretation could also explain lower burdens in GHSP relative to HOSP.

In summary, our data indicate that despite very different parasite burdens, both HOSP and GHSP maintain performance when infected with a coccidian parasite, even after burden is experimentally elevated in both species. However, the mechanism by which performance is preserved appears to differ physiologically between species. Introduced HOSP harbor large parasite burdens and cope with experimentally increased burden without adjusting allocation of an essential amino acid. The native species, on the other hand, appears to allocate critical 
nutrients differently among tissues depending on parasite ex $\rightarrow$ Dolnik O.V. 2006. The relative stability of chronic Isospora sylposure, perhaps in an effort to maintain burden at lower levels. We speculate that these differences may belie mechanisms whereby the HOSP can expand their range using parasites as weapons (Coon and Martin 2014; Martin et al. 2014). However, as GHSP exhibited similarly effective coping ability, the success of the invasive HOSP as mediated by interactions with parasites may be limited in areas of sympatry with congeners.

\section{Acknowledgments}

We thank Andrea Liebl and Onesmus Kioko for help with project development and data collection, Ellis Greiner for help with coccidia species identification, Jason Rohr for advice with statistics, and Richard McKinney for isotope sample analysis. We appreciate thoughtful comments about the manuscrip ${ }^{+}$ from Jason Rohr, Matt Venesky, Andrea Liebl, Brittany Sears, Martyna Boruta, Holly Kilvitis, and two anonymous reviewers. This work was funded by Graduate Women in Science (C.A.C.C.), the American Ornithologists Union (C.A.C.C.), and a National Science Foundation Research Coordination Network in Ecoimmunology Research Exchange (A.J.B., NSF-IOS 0947177; L.B.M., NSF-IOS 0920475).

\section{Literature Cited}

$\rightarrow$ Allen P.C. and R.H. Fetterer. 2002. Recent advances in biology and immunobiology of Eimeria species and in diagnosis and control of infection with these coccidian parasites of poultry $\rightarrow$ Clin Microbiol Rev 15:58-65.

$\rightarrow$ Altshuler D.L., K.C. Welch Jr., B.H. Cho, D.B. Welch, A.F. Lin, W.B. Dickson, and M.H. Dickinson. 2010. Neuromuscula: control of wingbeat kinematics in Anna's hummingbirds (Calypte anna). J Exp Biol 213:2507-2514.

$\rightarrow$ Blossey B. and R. Notzold. 1995. Evolution of increased competitive ability in invasive nonindigenous plants: a hypothesis. J Ecol 83:887-889.

Boughton D.C. 1933. Diurnal gametic periodicity in avian Isos $\rightarrow$ pora. Am J Hyg 18:161-184.

$\rightarrow$ Brawner W.R., III, G.E. Hill, and C.A. Sundermann. 2000. Effects of coccidial and mycoplasmal infections on carotenoid $\rightarrow$ based plumage pigmentation in male house finches. Auk 117: 952-963.

$\rightarrow$ Brown N.S. and G.I. Wilson. 1975. A comparison of the ectoparasites of the house sparrow (Passer domesticus) from North America and Europe. Am Midl Nat 94:154-165.

$\rightarrow$ Colautti R.I., I.A. Grigorovich, and H.J. MacIsaac. 2006. Propagule pressure: a null model for biological invasions. Biol Invasions 8:1023-1037.

$\rightarrow$ Coon C.A.C. and L.B. Martin. 2014. Patterns of haemosporidian prevalence along a range expansion in introduced Kenyan house sparrows, Passer domesticus. J Avian Biol 45:34-43.

Davidson N.C. 1979. A technique for protein reserve estimation in live redshank Tringa totanus. Wader Study Group Bull 27: 14-15. vianthina (Protozoa: Apicomplexa) infection in blackcaps (Sylvia atricapilla): evaluation of a simplified method of estimating isosporan infection intensity in passerine birds. $\mathrm{Pa}-$ rasitol Res 100:155-160.

Dolnik O.V., V.R. Dolnik, and F. Bairlein. 2010. The effect of host foraging ecology on the prevalence and intensity of coccidian infection in wild passerine birds. Neth Ornithol Union 98:97-103.

$\rightarrow$ Dolnik O.V. and H. Hoi. 2010. Honest signalling, dominance hierarchies and body condition in house sparrows Passer domesticus (Aves: Passeriformes) during acute coccidiosis. Biol J Linn Soc 99:718-726.

Dolnik O.V., V. Palinauskas, and S. Bensch. 2009. Individual oocysts of Isospora (Apicomplexa: Coccidia) parasites from avian feces: from photo to sequence. J Parasitol 95:169-174.

$\rightarrow$ Dunn A.M., M.E. Torchin, M.J. Hatcher, P.M. Kotanen, D.M. Blumenthal, J.E. Byers, C.A.C. Coon, et al. 2012. Indirect effects of parasites on invasions. Funct Ecol 26:1262-1274.

Greiner E. 1989a. Isospora, Atoxoplasma, and Sarcocystis. Pp. 108-119 in C.T. Atkinson, C.D. Thomas, and D. Hunter, eds. Parasitic diseases of wild birds. Wiley-Blackwell, Ames, IA. . 1989b. Parasite diagnosis by fecal examination. J Assoc Avian Vet 3:69-72.

Hill A.V. 1950. The dimensions of animals and their muscular dynamics. Sci Prog 38:209-230.

$\rightarrow$ Hõrak P., L. Saks, U. Karu, and I. Ots. 2006. Host resistance and parasite virulence in greenfinch coccidiosis. J Evol Biol 19:277-288.

Hõrak P., L. Saks, U. Karu, I. Ots, P.F. Surai, and K.J. McGraw. 2004. How coccidian parasites affect health and appearance of greenfinches. J Anim Ecol 73:935-947.

$\rightarrow$ Horns F. and M.E. Hood. 2012. The evolution of disease resistance and tolerance in spatially structured populations. Ecol Evol 2:1705-1711.

Kaiser A. 1993. A new multi-category classification of subcutaneous fat deposits of songbirds. J Field Ornithol 64:246255.

Kelly D.W., R.A. Paterson, C.R. Townsend, R. Poulin, and D.M. Tompkins. 2009. Parasite spillback: a neglected concept in invasion ecology? Ecology 90:2047-2056.

Kolar C.S. and D.M. Lodge. 2001. Progress in invasion biology: predicting invaders. Trends Ecol Evol 16:199-204.

$\rightarrow$ Komar N., S. Langevin, S. Hinten, N. Nemeth, E. Edwards, D. Hettler, B. Davis, R. Bowen, and M. Bunning. 2003. Experimental infection of North American birds with the New York 1999 strain of West Nile virus. Emerg Infect Dis 9:311322.

Kruszewicz A.G. 1995. The occurrence of Isospora lacazei (Coccidia: Eimeriidae) and its influence on nestling growth in house sparrows (Passer domesticus) and tree sparrows (Passer montanus). Pp. 291-305 in J. Pinowski, B.P. Kavanagh, and B. Pinowska, eds. Nestling mortality of granivorous birds due to microorganisms and toxic substances: synthesis. PWN, Warsaw.

$\rightarrow$ Lavin S.R., W.H. Karasov, A.R. Ives, K.M. Middleton, and T. 
Garland Jr. 2008. Morphometrics of the avian small intestin $\rightarrow$ O’Brien V.A., A.T. Moore, G.R. Young, N. Komar, W.K. Reisen, compared with that of nonflying mammals: a phylogenetic approach. Physiol Biochem Zool 81:526-550.

$\rightarrow$ Lee K.A. and K.C. Klasing. 2004. A role for immunology in invasion biology. Trends Ecol Evol 19:523-529. and C.R. Brown. 2011. An enzootic vector-borne virus is amplified at epizootic levels by an invasive avian host. Proc R Soc B 278:239-246.

$\rightarrow$ Lee K.A., L.B. Martin, D. Hasselquist, R.E. Ricklefs, and M. Wikelski. 2006. Contrasting adaptive immune defenses and blood parasite prevalence in closely related Passer species. Oecologia 150:383-392.

$\rightarrow$ Lee K.A., L.B. Martin, and M.C. Wikelski. 2005. Responding to inflammatory challenges is less costly for a successful avian invader, the house sparrow (Passer domesticus), than its less $\rightarrow$ invasive congener. Oecologia 145:244-251.

$\rightarrow$ Phillips B.L., C. Kelehear, L. Pizzatto, G.P. Brown, D. Barton, and R. Shine. 2010. Parasites and pathogens lag behind their host during periods of host range advance. Ecology 9:872881.

$\rightarrow$ Raberg L., A.L. Graham, and A.F. Read. 2009. Decomposing health: tolerance and resistance to parasites in animals. Philos Trans R Soc B 364:37-49.

$\rightarrow$ Reid W.M. 1990. History of avian medicine in the United States. X. Control of coccidiosis. Avian Dis 34:509-525.

$\rightarrow$ Levine N.D. 1982. Isospora passeris n. sp. from the house spar $\rightarrow$ Reisen W.K., Y. Fang, and V.M. Martinez. 2005. Avian host and row Passer domesticus, I. lacazei, and related apicomplexan protozoa. Trans Am Microsc Soc 101:66-74.

Lewis A. and D. Pomeroy. 1989. A bird atlas of Kenya. Balkema, Rotterdam.

$\rightarrow$ Lopez G., J. Figuerola, and R. Soriguer. 2007. Time of day, age and feeding habits influence coccidian oocyst shedding ir wild passerines. Int J Parasitol 37:559-564.

$\rightarrow$ Manwell R.D. 1957. Blood parasitism in the English sparrow, with certain biological implications. J Parasitol 43:428-433.

$\rightarrow$ Martin L.B., J.L. Alam, T. Imboma, and A.L. Liebl. 2010a. Variation in inflammation as a correlate of range expansion in Kenyan house sparrows. Oecologia 164:339-347.

$\rightarrow$ Martin L.B., A.J. Brace, A. Urban, C.A.C. Coon, and A.L. Liebl 2012. Does immune suppression during stress occur to promote physical performance? J Exp Biol 215:4097-4103.

Martin L.B., C.A.C. Coon, A.L. Liebl, and A.W. Schrey. 2014. Surveillance for microbes and range expansion in house sparrows. Proc R Soc B 281. doi:10.1098/rspb.2013.2690.

$\rightarrow$ Martin L.B., W.A. Hopkins, L.D. Mydlarz, and J.R. Rohr. $2010 b$. The effects of anthropogenic global changes on immune functions and disease resistance. Ann N Y Acad Sci 1195. 129-148.

$\rightarrow$ Martin L.B., L. Kidd, A.L. Liebl, and C.A.C. Coon. 2011. Captivity induced hyperinflammation in the house sparrow. J Exp Biol 214:2579-2685.

$\rightarrow$ Marzal A., R.E. Ricklefs, G. Valkiūnas, T. Albayrak, E. Arriero, C. Bonneaud, G.A. Czirjak, et al. 2011. Diversity, loss, ana gain of malaria parasites in a globally invasive bird. PLoS ONE 6:e21905. mosquito (Diptera: Culicidae) vector competence determine the efficiency of West Nile and St. Louis encephalitis virus transmission. J Med Entomol 42:367-375.

$\rightarrow$ Restif O. and J.C. Koella. 2004. Concurrent evolution of resistance and tolerance to pathogens. Am Nat 164:E90-E102.

$\rightarrow$ Ricklefs R.E. 1996. Morphometry of the digestive tracts of some passerine birds. Condor 98:279-292.

Roff D.A. 1993. Evolution of life histories: theory and analysis. Chapman \& Hall, New York.

Ruiz M., D. Wang, B.A. Reinke, G.E. Demas, and E.P. Martins. 2011. Immunity in a natural population of female sagebrush lizards, Sceloporus graciosus. Herpetol J 21:131-134.

$\rightarrow$ Schrenzel M.D., G.A. Maalouf, P.M. Gaffney, D. Tokarz, L.L. Keener, D. McClure, S. Griffey, D. McAloose, and B.A. Rideout. 2005. Molecular characterization of isosporoid coccidia (Isospora and Atoxoplasma spp.) in passerine birds. J Parasitol 91:635-647.

$\rightarrow$ Sears B.F., J.R. Rohr, J.E. Allen, and L.B. Martin. 2011. The economy of inflammation: when is less more? Trends Parasitol 27:382-387.

$\rightarrow$ Slater C., T. Preston, and L.T. Weaver. 2001. Stable isotopes and the international system of units. Rapid Commun Mass Spectrom 15:1270-1273.

Stearns S.C. 1992. The evolution of life histories. Oxford University Press, New York.

Torchin M.E., K.D. Lafferty, A.P. Dobson, V.J. McKenzie, and A.M. Kuris. 2003. Introduced species and their missing parasites. Nature 421:628-630.

$\rightarrow$ McCue M.D. 2011. Tracking the oxidative and nonoxidative $\overrightarrow{ }$ fates of isotopically labeled nutrients in animals. BioScience 61:217-230.

$\rightarrow$ Veasey J.S., N.B. Metcalfe, and D.C. Houston. 1998. A reassessment of the effect of body mass upon flight speed and predation risk in birds. Anim Behav 56:883-889.

$\rightarrow$ McCue M.D., B. Arquisola, E. Albach, and E.D. Pollock. 2013. $\rightarrow$ Werner R.A. and W.A. Brand. 2001. Referencing strategies and Hens produce artificially enriched ${ }^{13} \mathrm{C}$ egg proteins for metabolic tracer studies. Int J Biol 5:69-84. techniques in stable isotope ratio analysis. Rapid Commun Mass Spectrom 15:501-519.

$\rightarrow$ McCue M.D., O. Sivan, S.R. McWilliams, and B. Pinshow. 2010 $\rightarrow$ Whitney K.D. and C.A. Gabler. 2008. Rapid evolution in inTracking the oxidative kinetics of carbohydrates, amino acids and fatty acids in the house sparrow using exhaled ${ }^{13} \mathrm{CO}_{2}$. J Exp Biol 213:782-789. troduced species, "invasive traits" and recipient communities: challenges for predicting invasive potential. Divers Distrib 14:569-580. 